\title{
OBSERVATIONS OF THE LOWER-TROPOSPHERIC TEMPERATURE PROFILES USING THREE WAVELENGTH $\mathrm{CO}_{2}$-DIAL
}

\author{
Yasukuni Shibata, Nagasawa Chikao, Makoto Abo \\ Tokyo Metropolitan University, Hino, Tokyo 1910065, Japan
}

\section{*Email: sibata@tmu.ac.jp}

\begin{abstract}
The eye-safe lower-tropospheric temperature profiler with three wavelength differential absorption lidar (DIAL) technique which can perform the continuous temperature profile observation through daytime and nighttime is conducted. The DIAL consists of a Nd:YAG laser pumped an OPG tuned around $1573 \mathrm{~nm}$ of an $\mathrm{CO}_{2}$ absorption line with $2 \mathrm{~mJ} /$ pulse at $400 \mathrm{~Hz}$ repetition rate and a receiving telescope of $25 \mathrm{~cm}$ diameter. In this paper, we show the result of continuous temperature profile observations over 25 hours from 0.39 to $2.5 \mathrm{~km}$ altitude in the lowertroposphere. We can see temporally the generation and disappearance of the temperature inversion layers in the planetary boundary layer.
\end{abstract}

\section{INTRODUCTION}

Continuous observations of the temperature profile of lower-troposphere are important for studies in the atmospheric science. The lidar is the most effective instruments for temperature profiling with high temporal and spatial resolutions. Different lidar techniques for measuring the atmospheric temperature profile have been developed, namely the rotational Raman lidar (RRL), the high-spectral resolution lidar (HSRL) technique and the DIAL ${ }^{1}$. In lower-troposphere observation, achievement of the high rejection rate for the Mie scattering signal is difficult for the RRL and the HSRL. In daytime observation, as the solar background noise is higher in UV and visible wavelength, high power laser is required.

The $1.6 \mu \mathrm{m} \mathrm{CO} 2$ absorption band has the reasonable absorption intensity for DIAL observations in the troposphere ${ }^{2-4}$. We added a third wavelength for temperature measurement to the conventional two-wavelength DIAL. In addition to $\lambda_{\text {on }}(1572.992 \mathrm{~nm})$ and $\lambda_{\text {off }}(1573.137$ $\mathrm{nm})$, the third wavelength $\lambda_{\mathrm{T}}(1573.040 \mathrm{~nm})$ for temperature measurement is adopted to the offcenter absorption line. Temperature profiles by the DIAL technique can be obtained from the ratio of receiving signals $\lambda_{\mathrm{T}}$ and $\lambda_{\text {on }}$.

$$
\begin{gathered}
\frac{S_{T}(z)}{S_{o n}(z)}=\frac{E_{T}}{E_{o f f}} \exp \left\{-2 \int_{0}^{z} n_{c o 2}(Z) \Delta \sigma d Z\right\} \\
\Delta \sigma=\sigma_{o n}(T, z)-\sigma_{T}(T, z)
\end{gathered}
$$

The atmospheric temperature $T(z)$ is calculated from the $\mathrm{CO}_{2}$ density $n_{\mathrm{CO} 2}(\mathrm{z})$ which obtained from conventional DIAL technique and the differential absorption cross section $\Delta \sigma$.

\section{TEMPERATURE OBSERVATIONS}

This DIAL system is composed of an optical parametric generator (OPG) transmitter excited by a laser-diode pumped Nd:YAG laser. The partial power of $\lambda_{\text {on }}$ and $\lambda_{\mathrm{T}}$ injection seeders were as split off and directed through wavelength-controlled units, respectively. Three injection seeders, which are DFB lasers, are connected to an optical fiber switch. The output seeder wavelength is switched for every shot in turn of $\lambda_{\text {on }}, \lambda_{\text {off }}$ and $\lambda_{\mathrm{T}}$. The atmospheric backscatters are collected by $25 \mathrm{~cm}$ diameter telescopes and bandwidth of the interference filter is $1 \mathrm{~nm}$ FWHM. The optical receiver includes a near-infrared PMT operating in the analog mode.

Atmospheric temperature observations were conducted from 0.39 to $2.5 \mathrm{~km}$ by the three wavelength DIAL in $21-22$ April 2018 at the Hino campus of Tokyo Metropolitan University $(35.7 \mathrm{~N}, 139.4 \mathrm{E})$. It was covered with high pressure during the observation period, it was fine and the wind was weak. Figure 1 shows 
temperature profiles with an integration time of 30 minutes. Temperatures between the ground and $0.39 \mathrm{~km}$ of the DIAL minimum altitude were interpolated. There is the stable boundary layer at $0.75 \mathrm{~km}$ altitude and the inflection point of the temperature gradient at an altitude of $1.5 \mathrm{~km}$ until 6:00 LT. The temperature on the ground is lower than $0.39 \mathrm{~km}$ altitude between 2:00LT and 6:00LT. The surface inversion layer is appearing in this time. After sunrise (5:00 LT), the surface temperature increased, and the inversion layers disappeared. After sunset (18:23 LT), an inversion layer was formed again at an altitude of $0.6 \mathrm{~km}$. Typical diurnal variations of temperature profiles in fine weather were observed in detail.

\section{DISCUSSION AND CONCLUTION}

We have developed three wavelengths $1.6 \mu \mathrm{m}$ DIAL system for measurements of the atmospheric temperature profiles with the $\mathrm{CO}_{2}$ mixing ratio in the lower-troposphere. This DIAL conducted measurements of a diurnal variation of temperature profile on 21 - 22 April, 2018 from 0.39 to $2.5 \mathrm{~km}$ altitude. At an altitude of $1.5 \mathrm{~km}$ or less, the inflection point of the temperature gradient and the existence of a clear inversion layer were observed.
Usually nocturnal surface inversion layer height is lower than $100 \mathrm{~m}$, but observed inversion layer height is higher than this. This result will be explained following mechanism. Our observation site is located at the west edge of the Kanto plain. The north and west boundaries of the plain consist of high mountains while the other sides face the Pacific Ocean. Numerical results show cold air accumulation in the western parts of the plain ${ }^{5}$. The accumulated cold air generated a deep surface inversion layer.

\section{ACKNOWLEDGEMENTS}

This work was financially supported by the System Development Program for Advanced Measurement and Analysis of the Japan Science and Technology Agency.

\section{REFERENCES}

[1] A. Behrendt, Range Resolved Optical Remote Sensing of the Atmosphere, Springer, New York, (2005).

[2] D. Sakaizawa, et al., Appl. Opt. 48, 748-757 (2009).

[3] Y. Shibata, et al., Appl. Opt.,56, 1194-1201 (2017).

[4] Y. Shibata, et. al., Sensors 18, 4064 (2018).

[5] H. Kondo, J. of Appl. Meteor., 34, 1439 (1994)
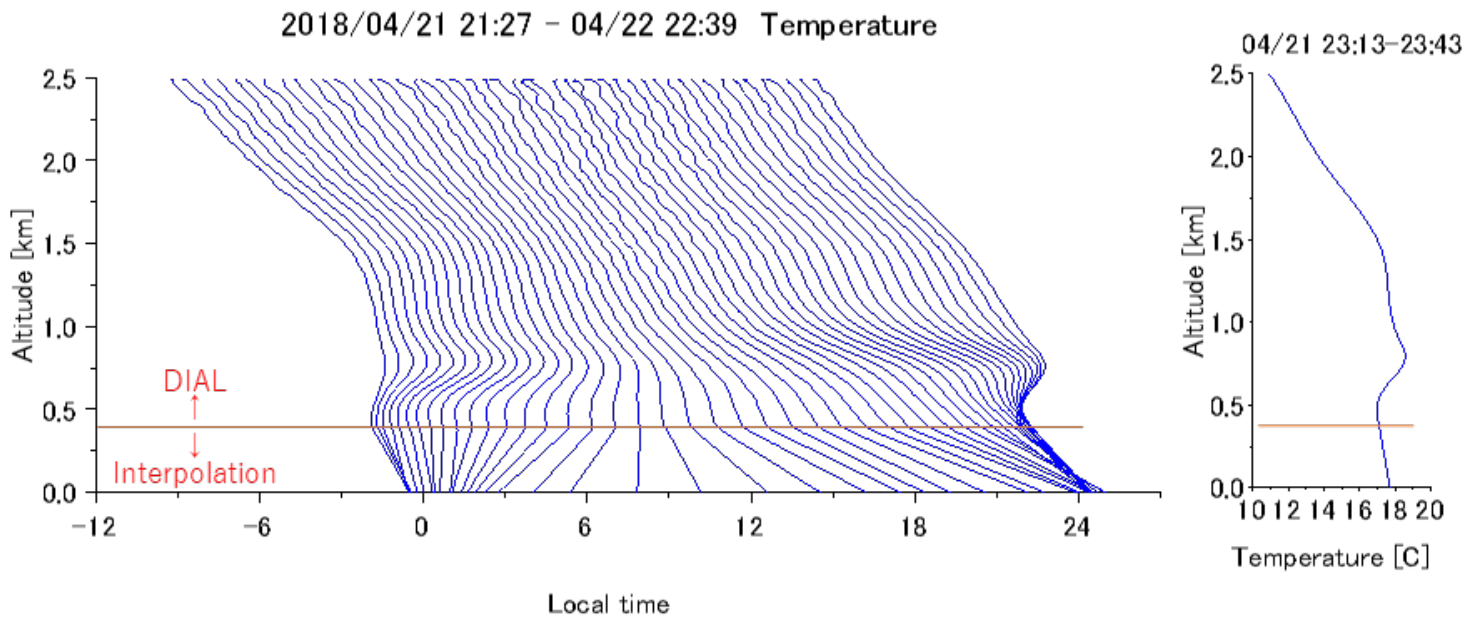

Figure 1 Atmospheric temperature profiles with an integration time of 30 minutes obtained from three wavelength $\mathrm{CO}_{2}$ DIAL on 21-22 April 2018. 